\title{
«Моцарт психологии»
}

\section{Интервью с Л.А. Вербицкой,}

доктором филологических наук, профессором, Президентом Российской академии образования, Президентом Санкт-Петербургского государственного университета, посвященное 120-летию со дня рождения Льва Семеновича Выготского (1896-1934 гг.)

\section{«Mozart of psychology»}

Interview with L.A. Verbitskaya

Doctor of Philology, Professor, President of the Russian Academy of Education, the President of the St. Petersburg State University, is dedicated to the 120th anniversary of Lev S. Vygotsky's birth (1896-1934).

Received September 20, 2016 / Accepted for publication: September 25, 2016\#

\begin{abstract}
интервью раскрывается вклад Л.С. Выготского в науку и образование, рассмотрены его главные научные достижения. Показано, что его новаторские концепции в педагогике и психологии намного опередили время и по сей день являются актуальными. Л.С. Выготский выдвинул идеи, которые раскрыли законы культурного развития личности, ее психических функций (речи, внимания, мышления), объяснили внутренние психические процессы ребенка, его отношения с окружающей средой. Ученый ввел в науку целый ряд понятий и концептов, на которые опирается современная психология и педагогика, такие как «высшие психические функции», «интериоризация», «опосредование», «сигнификация» и др.

Отмечается необычайная разносторонность Л.С. Выготского - он известен не только как психолог, но и как философ, методолог, педагог, дефектолог и даже как автор блистательных театральных рецензий и литературный критик. Также идет речь о том, как происходило становление Л.С. Выготского как ученого, приведень основные факты его биографии.

Продемонстрирована важность идей Л.С. Выготского для развития образовательного процесса. Указывается, что ученый заложил важнейшие принципы обучения ребенка, что такие разработанные им понятия, как «зона ближайшего развития», «социальная ситуация развития», «критические возрасты», «сензитивные периоды в развитии ребенка» до сих успешно используются ведущими психологами и педагогами, что он внес огромный вклад в развитие представлений о происхождении и развитии речи, о ее роли в развитии мышления.

Подчеркивается, что под непосредственным или косвенным влиянием Выготского сформировались взгляды целой плеяды известных отечественных ученых. Ближайшими учениками и соратниками Выготского были автор теории деятельности А.Н. Леонтьев, всемирно известный нейропсихолог А.Р. Лурия, автор концепции психического развития ребенка Д.Б. Эльконин, автор теории поэтапного формирования умственных действий П.Я. Гальперин.

Отмечается широкая международная известность Л.С. Выготского - его труды переведены, как минимум, на 19 языков. Научные центры и институты, базирующиеся на подходе Выготского и развивающие его идеи, существуют сегодня во многих странах - во Франции, Португалии, Бразилии, Анголе. Его идеям посвящены научные семинары, конференции и конгрессы в самых разных уголках мира.
\end{abstract}

Ключевые слова: Л.С. Выготский, история психологии, педагогическая психология, психология развития.

\begin{abstract}
Whe interview reveals the contribution of Lev Vygotsky in science and education, his main scientific achievements being drawn particular attention to. His innovative L concepts in pedagogy and psychology are far ahead of time and are relevant up today. Lev Vygotsky put forward ideas that disclosed the principles of cultural development of human individual, his/her mental functions (speech, attention, thinking), and explained the internal mental processes of the child, their relationship with the environment. Lev Vygotsky introduced a number of terms and concepts that are the basis of modern psychology and pedagogy. Among them there are «higher mental functions», «interiorization», «mediation», «signification», etc

There extraordinary versatility Lev Vygotsky is emphasized in the paper. He is known not only as a psychologist, but also as a philosopher, methodologist, teacher, therapist, and even as the author of the brilliant theater and literary reviews. There are also facts about Vygotsky's scientific path and his biography.

The importance of Vygotsky's ideas in the development of the educational process is highlighted. The scientist laid the most important principles of the child education. Such concepts developed by him as «zone of proximal development», "social situation of development», "critical age», «sensitive periods in the child development» are still successfully used by leading psychologists and educators. He made a huge contribution to the development of ideas about the origin and development of speech, its role in the development of thinking.

The whole galaxy of prominent scientists were raised under the influence of Vygotsky. Closest students and colleagues were the author of the activity theory A.N. Leontyev, the world-renowned neuropsychologist A.R. Luria, the author of the concept of the child's mental development D.B. El'konin, the author of the theory of stage development of mental activity P.Ya. Galperin.

Lev Vygotsky is famous on the international scale: his works are translated into 19 languages. Research centers and institutes based on the approach of Vygotsky and developing his ideas exist today in many countries, e.g. in France, Portugal, Brazil, Angola. Seminars, conferences and congresses in different parts of the world are devoted to his ideas scientific.
\end{abstract}

Keywords: Lev Vygotsky, history of psychology, educational psychology, developmental psychology. 


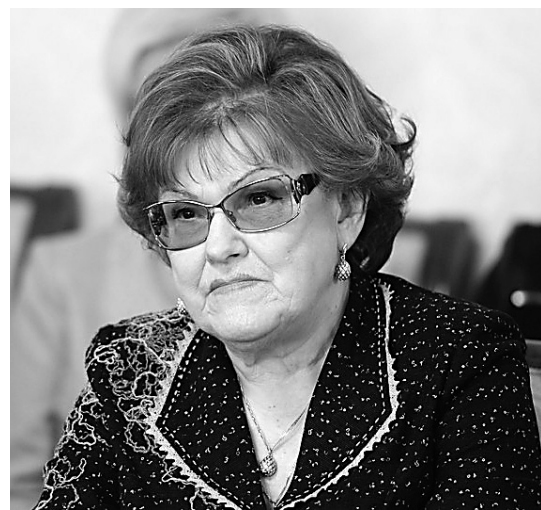

Людмила Алексеевна, в этом году исполняется 120 лет со дня рождения выдающегося ученого - Льва Семеновича Выготского. Что значит это имя для науки и образования? Каковы главные научные достижения Выготского?

Лев Семенович Выготский - выдающийся русский психолог начала ХХ века. Его новаторские идеи и концепции в педагогике и психологии намного опередили время.

Изучая развитие детей, ученый создал или развил несколько направлений: педологию и коррекционную педагогику. На основании его идей была создана новая демократическая школа. В его трудах нашли отражение проблемы психического развития ребенка, мышления и речи, эмоций, развития высших психических функций - памяти, внимания, восприятия и др., патологий психического развития. Его теоретические разработки и наблюдения легли в основу практических систем известных педагогов (например, Д.Б. Эльконина). Начатые Выготским исследования продолжили его ученики и последователи, давая им практическое применение. Особенно актуальными его идеи видятся сейчас. Занимаясь педагогикой, ученый увлекся новой наукой педологией (знания о ребенке с точки зрения разных наук) и стал главным педологом страны. Он считал, что любой педагог должен строить свою работу с опорой на психологическую науку.

Л.С. Выготский выдвинул идеи, которые раскрыли законы культурного развития личности, ее психических функций (речи, внимания, мышления), объяснили внутренние психические процессы ребенка, его отношения с окружающей средой. Его идеи по дефектологии положили начало коррекционной педагогики, которая стала практически помогать особым детям.

Выготский не разрабатывал методику воспитания и развития детей, но его концепции правильной организации обучения и воспитания стали основой многих развивающих программ и систем.

О разносторонности ученого свидетельствуют названия наиболее известных его работ - «Педагогическая психология», «Пихология искусства», «История развития высших психических функций», «Исторический смысл психологического кризиса», «Теория эмоций», «Основы дефектологии», «Мышление и речь».

Выготский ввел в науку целый ряд понятий и концептов, на которые опирается современная психология и педагогика, такие как «высшие психические функции», «зона ближайшего развития», «интериоризация», «опосредование», «сигнификация» и др.

\section{В чем уникальность теории, которую} предложил миру Л.С. Выготский?

Лев Семенович Выготский - одна из ярчайших звезд отечественной психологии. Именно Выготский создал уникальное направление, не имеющие ничего общего с существовавшими ранее трактовками становления человеческой личности. В 30-х годах в мире психологии и психиатрии каждый знал это имя Выготский Лев Семенович. Труды этого человека произвели фурор.

В первую очередь, речь идет о необычайной разносторонности ученого он известен не только как психолог, но и как философ, методолог, педагог, дефектолог и даже как автор блистательных театральных рецензий и литературный критик.

Основные труды исследователя: «Пихология искусства», «Мышление и речь», «Психология развития ребенка», «Педагогическая психология». Круг интересов ученого со всей очевидностью сформировал его подход к психологическим исследованиям. Человек, увлеченный искусством и языкознанием, одаренный педагог, любящий и понимающий детей.

Кроме того, Выготский отличался удивительной работоспособностью - казалось бы, достижения всех мыслителей прошлого и его современников нашли отражение в его многочисленных работах.

Он был одновременно блестящим исследователем, выдающимся теоретиком, практиком и ярким преподавателем. Не осталось, пожалуй, ни одной области в психологии и педагогике, которая ускользнула бы от его внимания. Благодаря выразительной характеристике, данной Выготскому британским философом Стивеном Тулмином, весь мир называет его Моцартом психологии.

Как происходило становление Л.С. Выготского как ученого?

Жизненный и творческий путь Выготского был необыкновенно ярким и, к сожалению, очень недолгим. Детство он провел в белорусском городе Гомеле, где получил прекрасное образование, как в лицее, так и в семье, в которой помимо него было еще семь детей.

Его отец также взял на себя заботу о детях своего умершего брата, один
ISSN 2079-6617 Print | 2309-9828 Online

(c) Lomonosov Moscow State University, 2016

๑ Russian Psychological Society, 2016 
из которых - Давид - позднее стал известным поэтом и литературоведом. По одной из версий, Лев, чья фамилия по рождению была «Выгодский», через «д», позднее изменил в своей фамилии одну букву именно для того, чтобы его не путали с уже достаточно известным к тому времени двоюродным братом. Л.С. Выготский был настоящим полиглотом: уже в Гомеле он, помимо русского, изучил шесть языков - немецкий, английский, французский, латынь, иврит и древнегреческий. Благодаря этому, впоследствии он мог читать всю необходимую ему научную литературу в подлиннике, на разных языках. Вообще, надо отметить, что в его семье культивировался интерес к языку и литературе - две его сестры стали лингвистами и авторами русско-английского и русско-французского словарей.

После окончания лицея, в 1913 году, Лев Семенович поступил в Московский университет на медицинский факультет по желанию своих родителей, но уже через месяц перевелся на юридический факультет. Параллельно он учился на историко-филологическом факультете такого примечательного заведения, как Народный университет А.Л. Шанявского, куда каждый желающий, вне зависимости от своего социального происхождения и образования мог поступать без экзаменов. В этом университете преподавали В.И. Вернадский, В.Я. Брюсов, Ю.И. Айхенвальд и другие известные профессора, многие из которых покинули Московский университет в 1911 году в знак протеста против политики царского министра народного образования.

В период учебы в университетах главным интересом Л.С. Выготского было литературоведение - он написал целый ряд критических әссе, среди которых наиболее известен анализ шекспировского «Гамлета». Этот интерес к литературному анализу положил начало разработке Львом Семеновичем основ психологии искусства, впоследствии ставшей темой его диссертации, которую он защитил в Москве в 1925 году. В родном Гомеле, куда Л.С. Выготский вернулся после учебы в Москве, его главным научным интересом ста- новится психология, и ему предоставляется возможность на практике воплощать и верифицировать свои теоретические предположения - он преподает в различных учебных заведениях, обследует детей, в том числе с дефектами развития и дает консультации. Итогом его научной и практической деятельности в Гомеле становится первая систематизация его идей в психологии и педагогике - работа «Педагогическая психология».

В 1924 году Выготский выступает на Всероссийском съезде по психоневрологии в Петрограде сразу с тремя докладами, один из которых посвящен результатам анкетирования школьников выпускных классов в Гомеле, а второй - вопросам преподавания психологии. Анкета, результаты которой были представлены в одном из докладов, была признана рецензентами «образцовой для подобного исследования». В анкете школьникам предлагалось ответить на вопросы о своих внешних данных, семье, школе, религии, национальности, профессиональных предпочтениях, политике, любви и «половом вопросе», планах на будущее и «душевном настроении». Полученные результаты обнаружили значительный сдвиг в настроениях молодежи по отношению к старшему поколению, вызванный влиянием Октябрьской революции.

Благодаря блестящему выступлению, л.С. Выготский получает предложение работать в Москве, где приступает к интенсивной разработке теоретических и прикладных проблем психологии и педагогики, и где он будет работать последнее десятилетие своей жизни. В московский период он разрабатывает проблему сознания, критически анализирует направления, существующие в психологии, занимается вопросами педагогической психологии и дефектологии, методологическими вопросами психологии.

Сразу после прибытия в Москву он принимает активное участие в создании дефектологической службы, в результате чего в 1929 году здесь будет создан Институт экспериментальной дефектологии, где Л.С. Выготский проработает до конца своих дней. Об- учение детей с «дефектами» развития - глухонемых, отстающих в развитии, было важнейшей сферой его деятельности. Разработанный им принцип «компенсации» дефекта и сегодня лежит в основе клинической реабилитации и педагогического подхода к обучению детей с проблемами в развитии. Институт существует по сей день под названием Института коррекционной педагогики.

В Москве Л.С. Выготский становится членом редколлегий множества изданий: его блестящие предисловия сопровожадают переводы известных зарубежных психологов и педагогов (Торндайка, Фрейда, Коффки и др.)

Именно в эти годы опубликованы его собственные важнейшие труды, как подготовленные в гомельский период его жизни («Пихология искусства» и «Педагогическая психология»), так и новые. В последние годы жизни Выготский изучает высшие психические функции (мышление, память, внимание, восприятие...) и их развитие, происхождение и строение сознания, а также уделяет много времени и сил развитию психолого-педагогического подхода. На протяжении почти половины своей короткой жизни Лев Семенович страдал туберкулезом, от обострения которого и скончался в возрасте 37 лет, оставив после себя научное наследие, которое до сих пор является предметом научных споров и источником новых идей, подходов и теорий в различных областях гуманитарного знания.

Как получилось, что имя Л.С. Выготского было забыто на долгие годы?

Действительно, только несколько работ Л.С. Выготского были опубликованы вскоре после его смерти, а затем в связи с репрессиями в науке в эпоху сталинизма его работы и имя были под запретом на долгие 20 лет.

Нападки на Выготского начались еще при его жизни, и были связаны, в первую очередь, с его работами по педологии - популярному в те годы направлению науки, объединявшему различные подходы (медицинский, психологический, биологический, педагогический) к развитию ребенка. В 1930-е годы он 
наряду с другими ведущими советскими специалистами, развивающими это направление, был обвинен в так называемых «педологических извращениях». Многие специалисты были уволены со своих рабочих мест, а впоследствии отправлены в лагеря. Есть мнение, что преждевременная смерть Л.С. Выготского спасла его от подобной участи.

Только после смерти Сталина стала вновь возможной публикация трудов Выготского: в 1956 году были опубликованы его «Избранные психологические исследования», сопровождавшиеся вступительной статьей его ближайших коллег А.Н. Леонтьева и А.Р. Лурии. Но лишь спустя много лет, в 1982-84 годах в издательстве «Педагогика» впервые вышло собрание сочинений Льва Семеновича в 6 томах.

Почему идеи Л.С. Выготского по-прежнему актуальны для образовательного прочесса?

В последние годы своей жизни Лев Семенович сосредоточился именно на проблеме обучения и развития. Проанализировав все известные подходы к связи обучения с умственным развитием детей, он заложил важнейшие принципы обучения ребенка, главный из которых заключается в том, что хорошее обучение не «плетется в хвосте развития», а ведет его за собой; согласно Выготскому, один шаг в обучении может стоить 100 шагов в развитии. Все сделанные Л.С. Выготским открытия и выводы, касающиеся проблемы обучения и развития, актуальны и сегодня. Современные педагоги и психологи опираются в своей деятельности на такие разработанные им понятия, как «зона ближайшего развития», «социальная ситуация развития», «критические возрасты», «сензитивные периоды в развитии ребенка». Одна из последних работ Выготского была посвящена проблемам специфики обучения и умственного развития детей разных возрастов - не только в школьном, но и дошкольном возрасте. Как известно, в настоящее время дошкольному обучению в нашей стране сегодня уделяется специальное внимание, и подход Выготского не- обходимо учитывать при разработке принципов эффективного обучения и развития дошкольников

Людмила Алексеевна, как Вы оцениваете вклад Л.С. Выготского в проблему изучения роли языка в развитии ребенка? Выготский внес огромный вклад в развитие представлений о происхождении и развитии речи, о соотношении ее различных форм и ее роли в развитии мышления, что чрезвычайно важно для обеспечения успешного образовательного процесса.

Одной из наиболее значительных его работ была монография «Мышление и речь», опубликованная вскоре после смерти ученого. Опираясь на накопленный к тому времени в психологии фактический материал (исследования В. Келера, Ж. Пиаже), Выготский предлагает два пути изучения внутренней речи человека - одной из самых труднодоступных для изучения форм речи. Первый путь заключается в генетическом исследовании возникновения внутренней речи, а второй в сопоставлении трех функционально различных форм речи - письменной, диалогической устной и внутренней. В этом контексте особый интерес представляет заочная полемика Выготского с его современником швейцарским ученым Жаном Пиаже, описавшим феномен эгоцентрической речи ребенка. Сам же Пиаже, родившийся в том же году, что и Выготский, но проживший гораздо дольше, узнал о существовании своего оппонента и о его работах спустя десятилетия, только в конце 1950-х годов.

В отличие от Пиаже, который считал, что эгоцентрическая речь, пик которой приходится на 3-летний возраст, асоциальна по своей природе и постепенно отмирает к школьному возрасту, Л.С. Выготский пришел к выводу, что эгоцентрическая речь не исчезает, а интериоризируется, становится внутренней речью - важнейшим средством мышления личности.

Примечателен тот факт, что именно в Женевском университете, где трудился Пиаже, сегодня работает коллектив ученых, отстаивающих позиции Выготского в педагогике и педагогиче- ской психологии (профессора Бернар Шневли, Фредерик Ивон и др.).

Какое развитие получили идеи Л.С. Выготского в отечественной науке?

Под непосредственным или косвенным влиянием Выгосткого сформировались взгляды целой плеяды известных отечественных ученых. Ближайшими учениками и соратниками Выготского были автор теории деятельности Алексей Николаевич Леонтьев, впоследствии ставший первым деканом основанного в 1966 году факультета психологии МГУ имени М.В. Ломоносова, всемирно известный нейропсихолог Александр Романович Лурия, автор концепции психического развития ребенка Даниил Борисович Эльконин, автор теории поэтапного формирования умственных действий Петр Яковлевич Гальперин и многие другие, чьи идеи и подходы лежат в основе современной отечественной психологии и педагогики. В свою очередь, на работы этих ученых опираются многие современные исследования, а также практические подходы в психологии и педагогике. В основу исследований и образовательного процесса на факультете психологии МгУ (декан - профессор Ю.П. Зинченко) всецело положен культурно-исторический подход Л.С. Выготского.

Известно ли имя Выготского зарубежным специалистам? Насколько популярен его подход за рубежом?

Сам Выготский выезжал за пределы страны только один раз - для участия в работе Международного конгресса в Лондоне по проблеме обучения глухонемых в Лондоне, посетив по дороге Германию и Францию. Тем не менее, уже при жизни его работы издавались на иностранных языках. В настоящее же время за рубежом наблюдается настоящий бум, связанный с его именем и его подходом. Согласно данным американских ученых, опубликованным в 2012 году, Выготский относится к числу самых цитируемых русскоязычных психологов в источниках на английском языке

В американской психологии интерес к идеям Выготского проявился еще в
ISSN 2079-6617 Print | 2309-9828 Online (C) Lomonosov Moscow State University, 2016 (c) Russian Psychological Society, 2016 
1970-е годы (работы Майкла Коула, Джеймса Верча). В период с 1987 по 1999 годы в США был издан перевод на английский язык собрания сочинений Выготского в шести томах.

Переводы работ Выготского на французский язык появились значительно позже, но в настоящее время ученые из франкоязычных стран мира активно развивают совершенно особый, отличный от североамериканского подход к анализу и применению идей Выготского (Люсьен Сэв, Бернард Шневли, Фредерик Ивон, Мишель Броссар, Фредерик Сосе и др.) Труды Л.С. Выготского переведены, как минимум, на 19 языков. Произведение «Мышление и речь» только на английском языке переиздавалось не менее 11 раз. На эту работу в англоязычных публикациях сделано более 20 тысяч ссылок. «Пихология искусства» на разных языках переиздавалась 16 раз.

Научные центры и институты, базирующиеся на подходе Выготского и развивающие его идеи, существуют сегодня во многих странах - во Франции, Португалии, Бразилии, Анголе. Его идеям посвящены научные семинары, конференции и конгрессы в самых разных уголках мира. Так, в какой-либо из франкоязычных стран раз в два года проводится Научный семинар «Выготский». В Португалии создано общество Выготского и Институт Выготского, по инициативе Президента которых профессора Жоакима Кинтино-Айреса, начиная с 2010 года, каждые два года проводится Международная конференция памяти Выготского.
Ведется ли дальнейшая разработка идей Л.С. Выготского?

Учитывая возраст, в котором оборвалась жизнь ученого, кажется естественным, что его теория осталась незавершенной. Этим объясняется тот факт, что разными учеными идеи Выготского интерпретируются по-разному, и ведутся постоянные научные дискуссии, связанные с осмыслением его идей. В связи с этим необходима дальнейшая систематизация наследия Выготского, требующая сопоставления подходов как отечественных, так и зарубежных ученых к пониманию его взглядов.

В настоящее время ведется работа над изучением архивов Выготского, материалы из которых в скором времени планируется опубликовать как на русском, так и на английском языках. Популярность Выготского и его идей в России и во всем мире не только не проходит с годами, а, напротив, все возрастает.

В одном из номеров Национального психологического журнала - 2014, №1(13) - (главный редактор Ю.П. Зинченко) специальный раздел посвящен обсуждению научного наследия Льва Семеновича .

Практически каждый год в разных странах мира выходят в свет научные монографии, посвященные творчеству Выготского и анализу и развитию его идей. Так, в 2012 году под редакцией академика РАО Ю.П. ЗинченкО и профессора Женевского университета Ф. Ивона на французском языке вышел в свет сборник ранее не переведенных статей Выготского в сопровождении текстов известных специалистов из России и франкоязычных стран Франции, Швейцарии, Канады, Бельгии. Сборник стал результатом многолетнего сотрудничества факультета психологии Мгу имени М.В. Ломоносова, факультета образования Университета Монреаля и Университета Женевы. Сборник получил многочисленные отклики и пользуется широкой популярностью среди франкоязычных специалистов и студентов.

Существуют ли какие-то инициативы по увековечиванию памяти Л.С. Выготского?

На родине Выготского, в Белоруссии, его имя уже носят улица в Минске и Государственный педагогический колледж в Гомеле, где Выготский провел детство и первые годы своей профессиональной деятельности после окончания Московского университета. В Москве, где Выготский жил и работал последние, наиболее продуктивные 10 лет своей жизни, имя Выготского носит Институт психологии РГгУ. Для увековечивания памяти Л.С. Выготского Российская академия образования обратилась к мэру г. Москвы С.С. Собянину с инициативой о присвоении его имени одной из улиц Москвы, а к Министру образования и науки Российской Федерации Д.В. Ливанову с просьбой об учреждении ведомственной награды Министерства образования и науки Российской Федерации медали имени Л.С. Выготского.

Хотелось бы также предложить, чтобы Институту коррекционной педагогики, созданному благодаря активному участию Выготского, также было присвоено его имя.
ISSN 2079-6617 Print | 2309-9828 Online (c) Lomonosov Moscow State University, 2016 (C) Russian Psychological Society, 2016 